集》澺 テ 邚 $三$ 磞以八

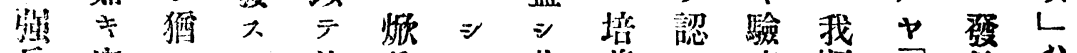

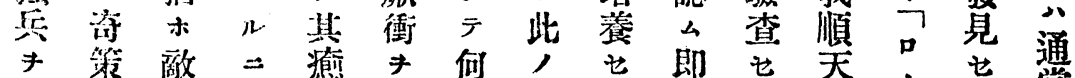

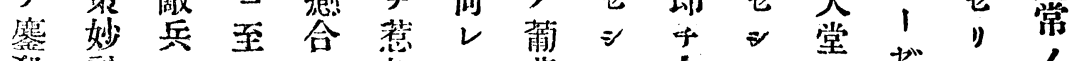

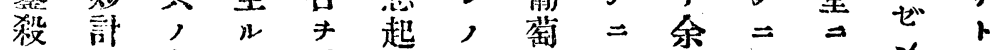

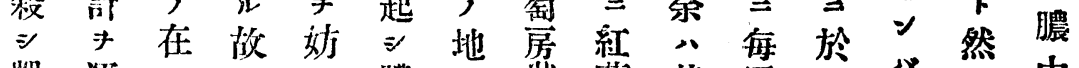

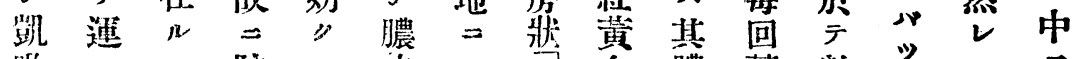

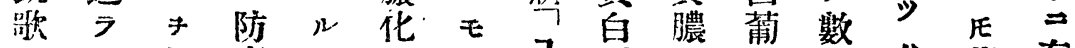

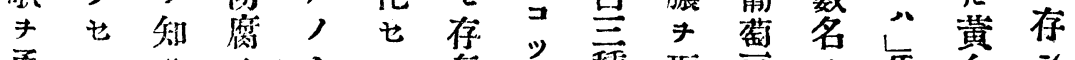

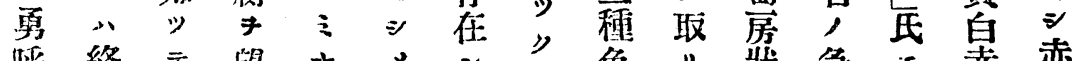

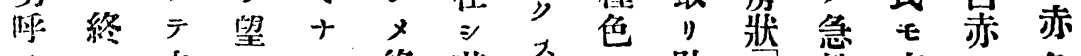

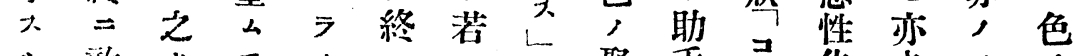

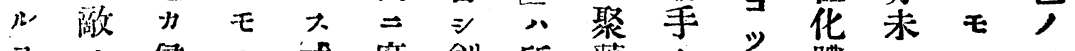
子, 侵, 或腐創所落卜”膿夕, モ

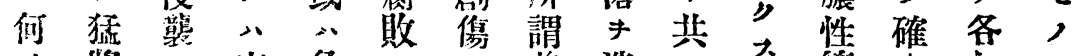

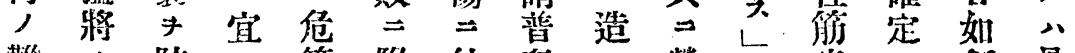

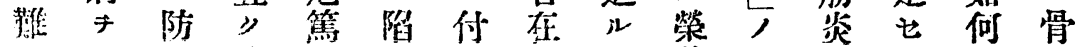
キ挫蓹茲,

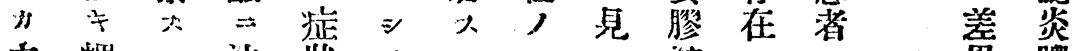
之蛸

严 宁

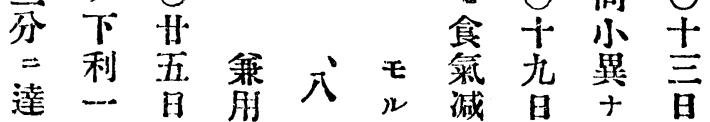
只嘿 七耗爽り來

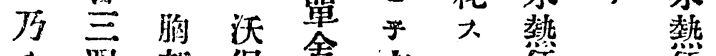
千四部保舍水筷 左行了杂利

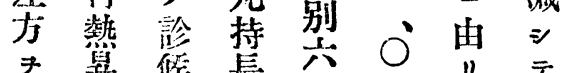
算候長爷 $O$ 少 處

大

午

前 $v$

形

八 䐪

度 加

年荅

后兒

州

九 㢸

度 $\approx$
○老左邢

幾鼠方度

帮鼠 改京

浸 四

O 0

0

门 稀

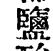

酸

4 八

度

,

間

$=$

在
熱

此
八
度

计

九

度

間

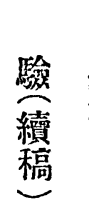

(a)

結

核

性

脯

焱

$\Rightarrow$

沃

度

木

2

4

$=$

昇

降

シ

諸

症

大

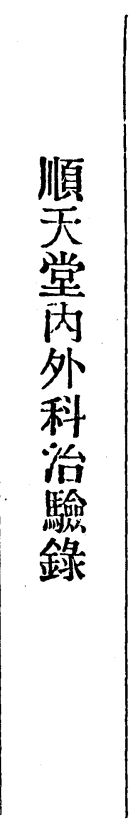


泡》 川爾用 $\bigcirc$

畐呼百后

低吸 $千$ 熱止

微卅至葴义日采時

队内人再

成外萝

リ $\neq$ 卅沃獭

且 算 $\Rightarrow$ 八 保秒

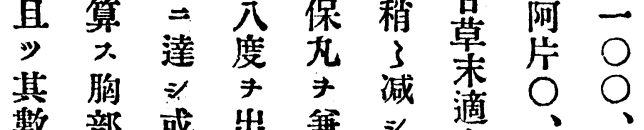

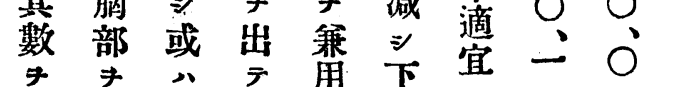

减 診 减 た

シ $大$ 沙脉 $又$ 全

粗 $\Rightarrow$ テ 整

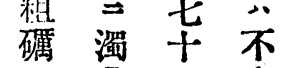

音 至 定

脯滥以 以

胞䔩下

音 三十 テ

及水成 或

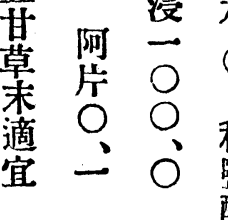

止 向 糖

譼

转.

萧

\section{筷 严}

○老止午空八阿 利 邓后 日

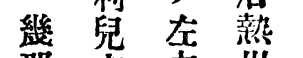

單 先

用那水方州頙舍幾

浸共丮瘦利一

稀

谓 度

․ 四度

面 留

利寒

份 浐

樕

i

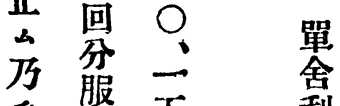

千服五. 利

格㔔

别

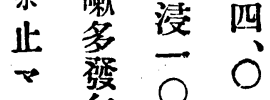

大. 午

万前

$千$ 趐

一 椞

時 入

牛度
利 天 夥 $大 テ$ 訴二明及

别多其新分治龙

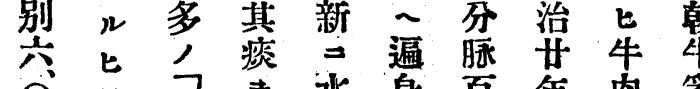

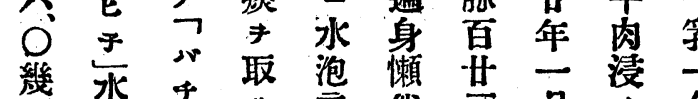

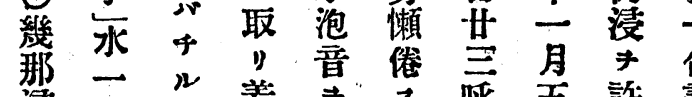

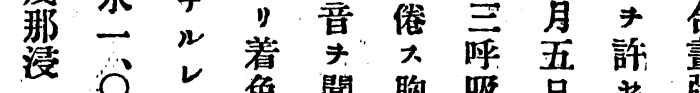

○ 老 こ色聞胸嗳星

○犁 $\approx$ 咳 $夫$ 七然

○兒認行濑診回惡

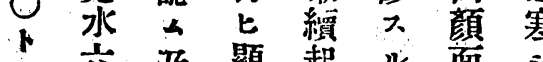

$=$ 六顯起

臨 0 女微稍 $\Rightarrow$ 潮熱

時 稀 前镜名左 紅 度

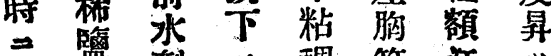

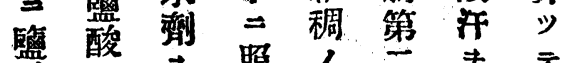

酸

、改見痰助布四

v 0 × $\neq$ 間 $\neq$

七單

+ 舍 $\Rightarrow$ 出於 $*$ 度
起 2 存成

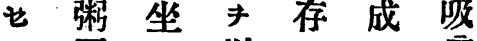

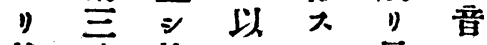

然碗快广ル量

鴙話十

二卵笑 三認挂 取

二談 $\overline{\text { 月 }}$ \$

個食甘食减咯

夜量七筑方痰

粥ノ日進撿

二不終吉㴑著

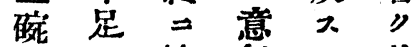

鴙 $三$ 撿氣 $⿻$ 其

卵訴 熱 爽 三 粘

二 $>$ ₹ 快稀 稠

茞依此病 $=$ 性 


\begin{tabular}{|c|c|c|c|c|c|c|c|c|c|c|c|c|c|c|}
\hline t. & 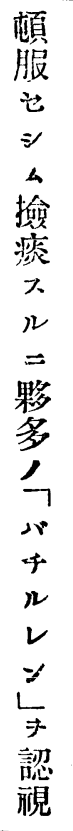 & 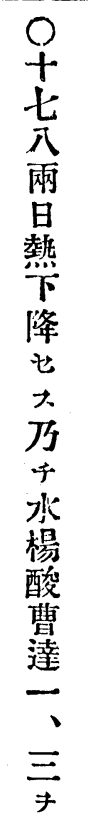 & 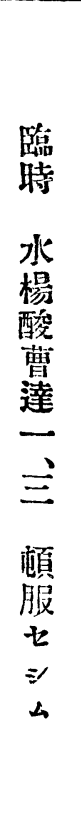 & $\begin{array}{l}x \\
\text {. }\end{array}$ & 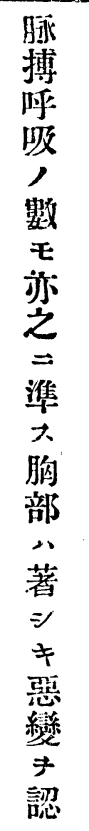 & 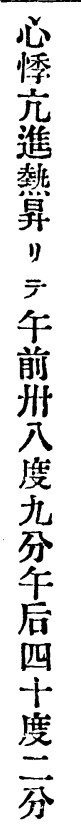 & 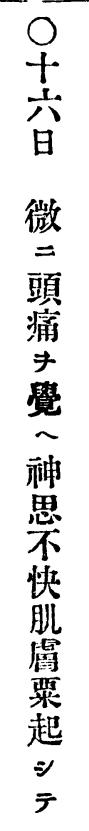 & 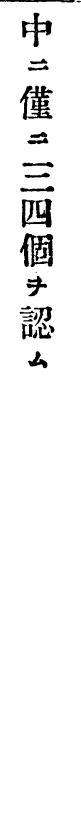 & 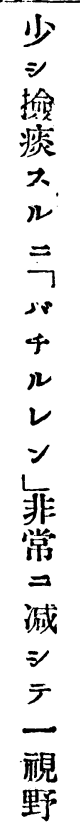 & 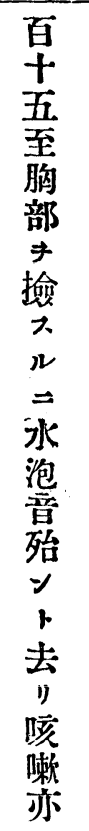 & 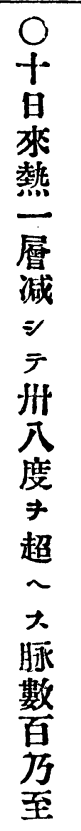 & 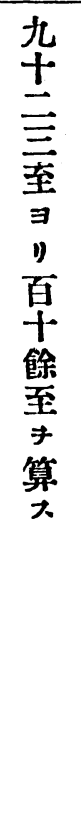 & 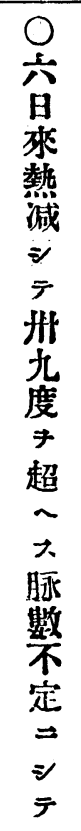 & 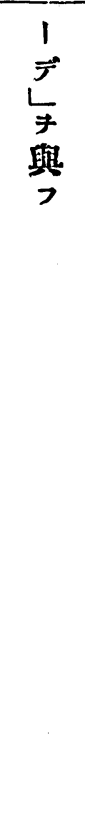 \\
\hline 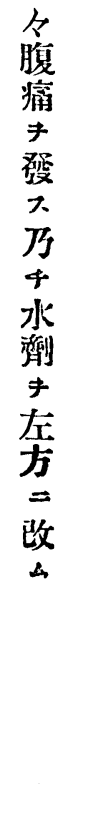 & 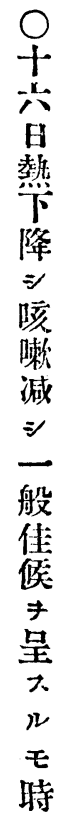 & 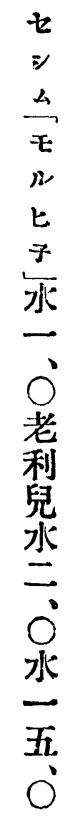 & 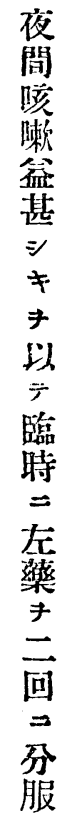 & & 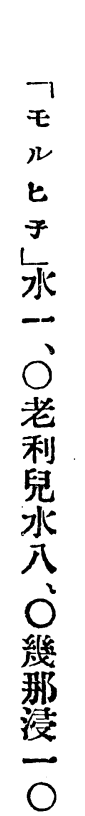 & 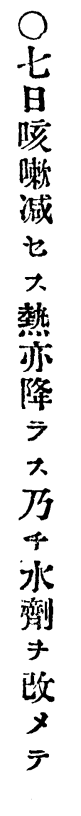 & $\begin{array}{c}\text { 分 } \\
\text { 服 } \\
\text { せ } \\
\text { シ } \\
\text { ん }\end{array}$ & 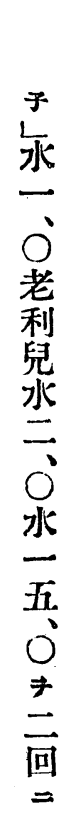 & 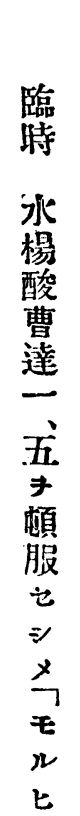 & 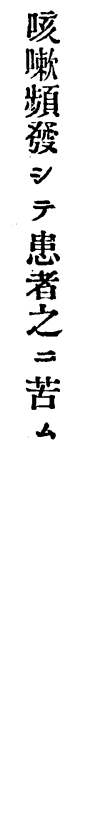 & 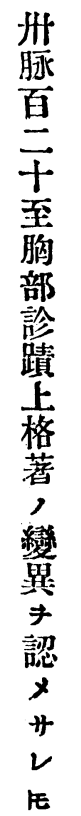 & 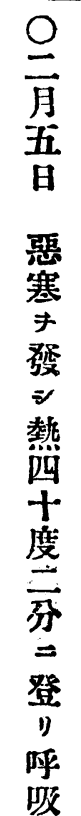 & 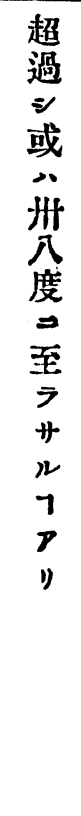 & 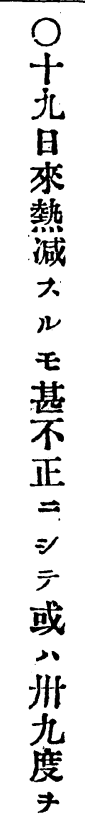 \\
\hline
\end{tabular}


〜遙, 音整シ神大爾

$\Rightarrow$ 七微全患肌思豚后

$=\equiv \Rightarrow \geqslant$ 著肉快搏熱

谷 又遺失徐肥濶亦度

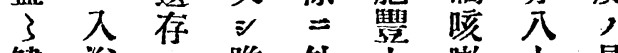

健浴大唯外夲濑十昇

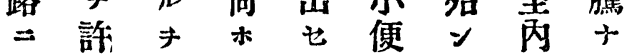

進三知肺ン人, 外》

三欲心胞 7 通失呼 $三$

殆大, 晋 $夫$ 利 $三$ 吸

江三人气順咯廿大

卜處故粗子調痚回抵

全 $;=$ 粘 胸 顏微 $尹$ 三

治聯日十部㼰少上十

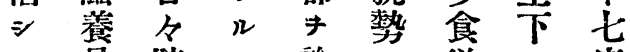

二嵒院卜診 $\neq$ 微 $三$ 度

㤉”內 打下增韭体五

喜適園診心嫦力分

实宜固上 $上$ 呼 $\Rightarrow$ 加 $\Rightarrow$

々 = 㯰 水吸䒕八超

院與逍音泡安進り

病試 万原不

性用䒨實了眠家亏龍

簡, 地治症新 1 動

簡 $\Rightarrow$ 法治燎

菓 = 潦法以 $=$ 过

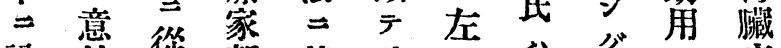

說多從新就殊, 壬㢳病

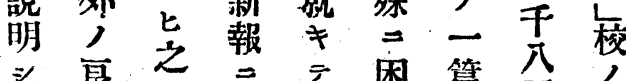

良之云三困篇分,

亚成沃揭近難。百藥

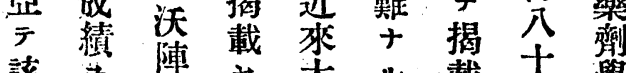

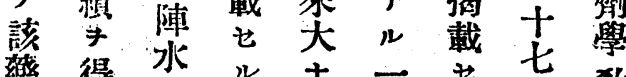

樂得水素只

人酸令困症

一故尔乎難 候

定 $\Rightarrow \quad \exists \quad x=1$

量余 $\exists$ 遭

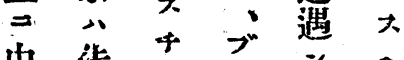

由 少

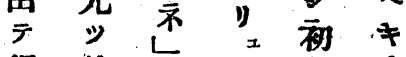

得 其 $三 1$ 疾

於

治!吉兵

療 。

于
万人 $\mathrm{O}$

4 世

○稀 水 $\mathrm{O} \bigcirc$ 老

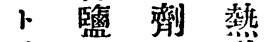

○利

i 兒

一改

○ $\underset{1}{\circ}$

單体

舍利復

别

亲

茂

娜

咳

濑

少

腹

痛

全

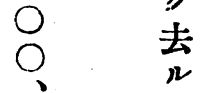

四

翡

沃

斯

丁

䖻

三

0

敖

浸

一

有

餘 䈥

日 记

* 1

經

外

渦 時

醫 吏

事 卅

$\mathrm{H}$

新 $=$

說

i)

テ

即

f

入

院

- 后

未 第

完 百 